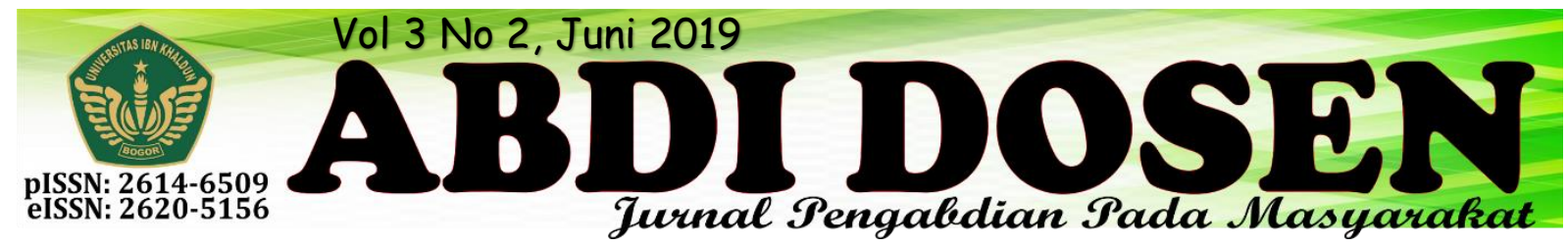

\title{
MENINGKATKAN KUALITAS SUMBER DAYA MANUSIA DI DESA \\ CIHIDEUNG ILIR MELALUI ASPEK PENDIDIKAN, SOSIAL DAN \\ EKONOMI YANG DI TUNJANG DENGAN PENGETAHUAN AGAMA DAN KESEHATAN
}

\author{
Prihatini Purwaningsih ${ }^{1}$, Ahmad Gozi, Aulia Fitriani, Bea Birrulwalidain ${ }^{2}$ \\ prihatini@uika-bogor.ac.id \\ Fakultas Hukum Universitas Ibn Khaldun ${ }^{1}$, Mahasiswa KKN Kelompok 17 Tahun $2018^{2}$
}

\begin{abstract}
ABSTRAK
Kuliah Kerja Nyata (KKN) adalah kegiatan mahasiswa dalam mengabdi kepada masyarakat dengan pendekatan lintas keilmuan dan sektoral pada waktu dan daerah tertentu. Pelaksanaan kegiatan KKN berlangsung kurang lebih selama satu bulan dan bertempat di Desa Cihideung Ilir Kecamatan Ciampea. Direktorat Jenderal Pendidikan Tinggi di Indonesia mewajibkan setiap perguruan tinggi untuk melaksanakan KKN sebagai kegiatan intrakurikuler yang memadukan tri dharma perguruan tinggi yaitu: pendidikan, penelitian, dan pengabdian kepada masyarakat. Sasaran KKN Tematik Terintegrasi bagi masyarakat yakni untuk meningkatkan kesadaran masyarakat dalam mengembangkan produktifitas sumber daya pembangunan dengan fasilitas yang ada. Kegiatan KKN Tematik Terintegrasi UIKA Bogor Tahun 2018 adalah salah satu kegiatan untuk masyarakat dimana pada pelaksanaan kegiatan ini melakukan proses perencanaan sekaligus aksi program Pendampingan masyarakat baik pada aspek sosial, ekonomi, kesehatan, pendidikan, dan agama maupun teknologi tepat guna secara terpadu. Kelompok 17 ini melakukan kegiatan KKN tematik terintegrasi di salah satu desa yang berada di kecamatan Ciampea tepatnya di Desa Cihideung Ilir. Adapun khalayak sasaran dari pemberdayaan masyarakat yang kami lakukan yaitu siswa-siswi sekolah yang ada di kampung tersebut meliputi PAUD, SD, SMP, dan SMA/SMK agar sadar tentang pentingnya aspek sosial, ekonomi, kesehatan, pendidikan, agama maupun teknologi dalam lingkungan masyarakat Cihideung Ilir.
\end{abstract}

Kata Kunci: KKN, Program Kerja, Sumber Daya Manusia.

\section{PENDAHULUAN}

Kuliah Kerja Nyata merupakan salah satu bagian dari sistem Pendidikan tinggi yang menempatkan Mahasiswa di luar Kampus agar mahasiswa hidup ditengahtengah masyarakat bersama masyarakat untuk membantu dan mendampingi masyarakat memanfaatkan potensi sumberdaya alam lokal dan sumber daya manusia yang ada untuk mengatasi permasalahan masyarakat dalam kurun waktu tertentu. KKN Tematik Terintegrasi UIKA Bogor merupakan sebuah tuntutan/kewajiban bagi mahasiswa semester VI. Sasaran KKN Tematik Terintegrasi bagi masyarakat yakni untuk meningkatkan kesadaran masyarakat dengan berperan aktif dalam mengembangkan produktifitas sumber 
daya pembangunan sesuai dengan fasilitas yang dimiliki. Lembaga Penelitian dan Pengabdian Masyarakat (LPPM) UIKA Bogor telah melaksanakan KKN Tematik rintegrasi pada tahun 2018 di Kabupaten Bogor.

Kegiatan KKN Tematik Terintegrasi UIKA Bogor Tahun 2018 merupakan salah satu kegiatan untuk masyarakat dimana pada pelaksanaan kegiatan ini melakukan proses perencanaan sekaligus aksi program Pendampingan masyarakat baik pada aspek sosial, ekonomi, kesehatan, pendidikan, hukum, dan agama maupun teknologi tepat guna secara terpadu.

Pada tanggal 7 Agustus s.d. 5 September 2018 kemarin telah terlaksanakan program Kuliah Kerja Nyata (KKN) Kel./Desa Cihideung Ilir, Kec. Ciampea, Kab. Bogor - Jawa Barat. Pada program KKN tersebut direalisasikanlah salah satu tri dharma perguruan tinggi yaitu pemberdayaan masyarakat. Tujuan dari pelaksanaan program ini yaitu diharapkan mahasiswa memperoleh pengalaman belajar melalui keterlibatan dalam masyakarat yang secara langsung menemukan, merumuskan, memecahkan dan menanggulangi permasalahan yang berada di lapangan. Adapun khalayak sasaran dari pemberdayaan masyarakat yang kami lakukan yaitu siswa-siswi sekolah yang ada di kampung tersebut meliputi PAUD, SD, SMP, dan SMA.

\section{Keadaan Geografis}

Desa Cihideung Ilir merupakan salah satu Desa di wilayah kecamatan Ciampea Kabupaten Bogor, dengan luas wilayah $178 \mathrm{Ha} / \mathrm{Km}^{2}$ yang terdiri dari $5 \mathrm{RW}$ dan 27 RT. Batas wilayah adalah sebagai berikut:

\begin{tabular}{|l|l|l|}
\hline No & \multicolumn{1}{|c|}{ Arah } & \multicolumn{1}{|c|}{ Batasan } \\
\hline 1 & Utara & $\begin{array}{l}\text { Desa } \\
\text { Cibanteng/Jalan } \\
\text { Provinsi }\end{array}$ \\
\hline 2 & Selatan & $\begin{array}{l}\text { Desa Cihideung } \\
\text { Udik }\end{array}$ \\
\hline 3 & Timur & $\begin{array}{l}\text { Desa } \\
\text { Babakan/Sungai } \\
\text { Cihideung }\end{array}$ \\
\hline 4 & Barat & $\begin{array}{l}\text { Desa Cihideung } \\
\text { Udik }\end{array}$ \\
\hline
\end{tabular}

Bidanglingkungan, permasalahannya yaitu Masyarakat masih membuang sampah sembarangan di sungai di desa Cihideung Ilir. Dimana dari pembuangan sampah sembarangan tersebut menyebabkan tercemarnya air disekitaran dan munculnya jentik nyamuk karna air yang menggenang khususnya di RW 02 RT 06, tercemarnya air sangat tidak sehat dan layak untuk masyarakat sekitar.

\section{Kondisi Masyarakat}

Jumlah penduduk Desa Cihideung Ilir tercatat sebanyak 10.184 Jiwa, terdiri dari:

\begin{tabular}{|c|l|l|}
\hline No & Jenis Kelamin & Jumlah \\
\hline 1 & Laki-laki & 5.704 \\
\hline 2 & Perempuan & 4.480 \\
\hline
\end{tabular}

Secara umum kondisi sosial serta keamanan dan ketertiban di wilayah Desa Cihideung Ilir cukup baik dan terkendali. Dalam hal ini, kehidupan warga masyarakat dapat tersalurkan sesuai dengan keadaan di Desa Cihideung Ilir. Berkaitan dengan masalah keamanan dan ketertiban, dapat disampaikan bawa situasi dan kondisi Desa Cihideung Ilir terbilang aman. Adapun masalah keamanan dan ketertiban yang terjadi antara lain: Pencurian sebanyak 2 kali.

$$
\text { Adapun jumlah anggota }
$$

perlindungan masyarakat (linmas) sampai saat ini tercatat sebanyak 10 orang. 
Kelembagaan linmas pada saat ini sudah adanya pengaturan tentang keberadaan linmas di tingkat Kabupaten Bogor.

Dalam bidang kesehatan adalah hanya tersedia 1 posyandu, kegiatan kesehatan posyandu dilaksanakan di rumah Ibu Kader Posyandu yang bertempat di RT 02 RW 02 dan terlalu jauh jangkauannya untuk RW lain.

\section{Tingkat Pendidikan Penduduk}

\begin{tabular}{|l|l|c|c|c|}
\hline No & $\begin{array}{c}\text { Keteran } \\
\text { gan }\end{array}$ & Total & $\begin{array}{c}\text { Laki- } \\
\text { Laki }\end{array}$ & $\begin{array}{c}\text { Perem } \\
\text { puan }\end{array}$ \\
\hline 1 & $\begin{array}{l}\text { Sekolah } \\
\text { Dasar }\end{array}$ & 3.789 & 1.855 & 1.934 \\
\hline 2 & SMP & 2.111 & 1.123 & 988 \\
\hline 3 & SMA & 2.024 & 1.198 & 826 \\
\hline 4 & PT & 343 & 215 & 128 \\
\hline
\end{tabular}

Di Desa Cihideung Ilir dalam pendidikan yaitu, sangat baik pada tingkat kesadaran dan kepedulian akan pentingnya pendidikan.

\section{METODE}

\section{Tahap pelaksanaan}

Prosedur pelaksanaan KKN Tematik Terintegrasi antara lain sebagai berikut:

a. Pembentukan kelompok program KKN Tematik Terintegrasi yang bekerja sama dengan Lembaga Penyelenggara Pemberdayaan Masyarakat.

b. Sosialisasi dan pendekatan peserta KKN Tematik Terintegrasi, pengurus Desa Cihideung Ilir dan tokoh masyarakat. Dengan pengenalan wilayah dan mencari tahu sistem dalam masyarakat baik dari segi berfikir, adat, bahasa, kepercayaan dan keseharian warga setempat.

c. Pembuatan Program Kerja KKN Tematik Terintegrasi sesuai masingmasing bidang. Program kerja yang dibuat dari hasil wawancara dengan
Bidang Eknomi

\begin{tabular}{|l|l|c|}
\hline No & Keterangan & Jumlah \\
\hline 1 & Buruh Industri & 2.150 \\
\hline 2 & PNS/ABRI & 124 \\
\hline 3 & Pedagang & 62 \\
\hline 4 & Buruh Bangunan & 60 \\
\hline 5 & Pengusaha & 400 \\
\hline 6 & Pensiunan & 28 \\
\hline 7 & Petani & 18 \\
\hline 8 & Buruh Tani & 29 \\
\hline 9 & Angkutan & 91 \\
\hline 10 & Lainnya & 7.222 \\
\hline
\end{tabular}

Cihideung Ilir adalah, kurangnya semangat dan motivasi dalam mengembangkan usaha, sehingga usaha yang berjalan di Desa Cihideung Ilir kurang berkembang, dan untuk "Bank Keliling" sempat ada namun sekarang sudah jarang.

tokoh masyarakat dan warga Desa Cihideung Ilir. Wawancara dilakukan untuk mendapatkan informasi melalui sesi tanya jawab yang terstruktur dan mempunyai fokus tersendiri agar jelas dan sesuai sasaran. Dengan mengajukan beberapa pertanyaan terhadap narasumber di lokasi yang berbeda dimana objek tersebut sekaligus di teliti oleh peserta KKN. Adapun narasumber yang dijadikan sumber informasi diantaranya yaitu bapak kepala desa beserta jajarannya, struktur pemerintahan warga: RW, RT, kader posyandu, tokoh agama setempat, karang taruna, tokoh masyarakat.

d. Sosialisasi dengan survey lapangan untuk melihat langsung lokasi sasaran atau kegiatan yang dilaksanakan 
dilokasi sasaran sehingga mendapat informasi sejelas-jelasnya. Sasaran lokasi pelaksanaan KKN Tematik Terintegrasi Kelompok 17 yaitu Desa Cihideung Ilir Kecamatan Ciampea. Sebelum melaksanakan KKN Tematik Terintegrasi peserta beserta DPL mengadakan survey terlebih dahulu kepihak desa dan mengadakan wawancara singkat terkait lokasi sasaran sehingga di putuskan bahwa kegiatan dilaksanakan di Desa Cihideung Ilir RT 06 / RW 02.

e. Pelaksanaan program kerja KKN Tematik Terintegrasi yang telah dibuat. Tahap pelaksanaan untuk kegiatan ini sebagaimana terlihat pada bang sebagai berikut:

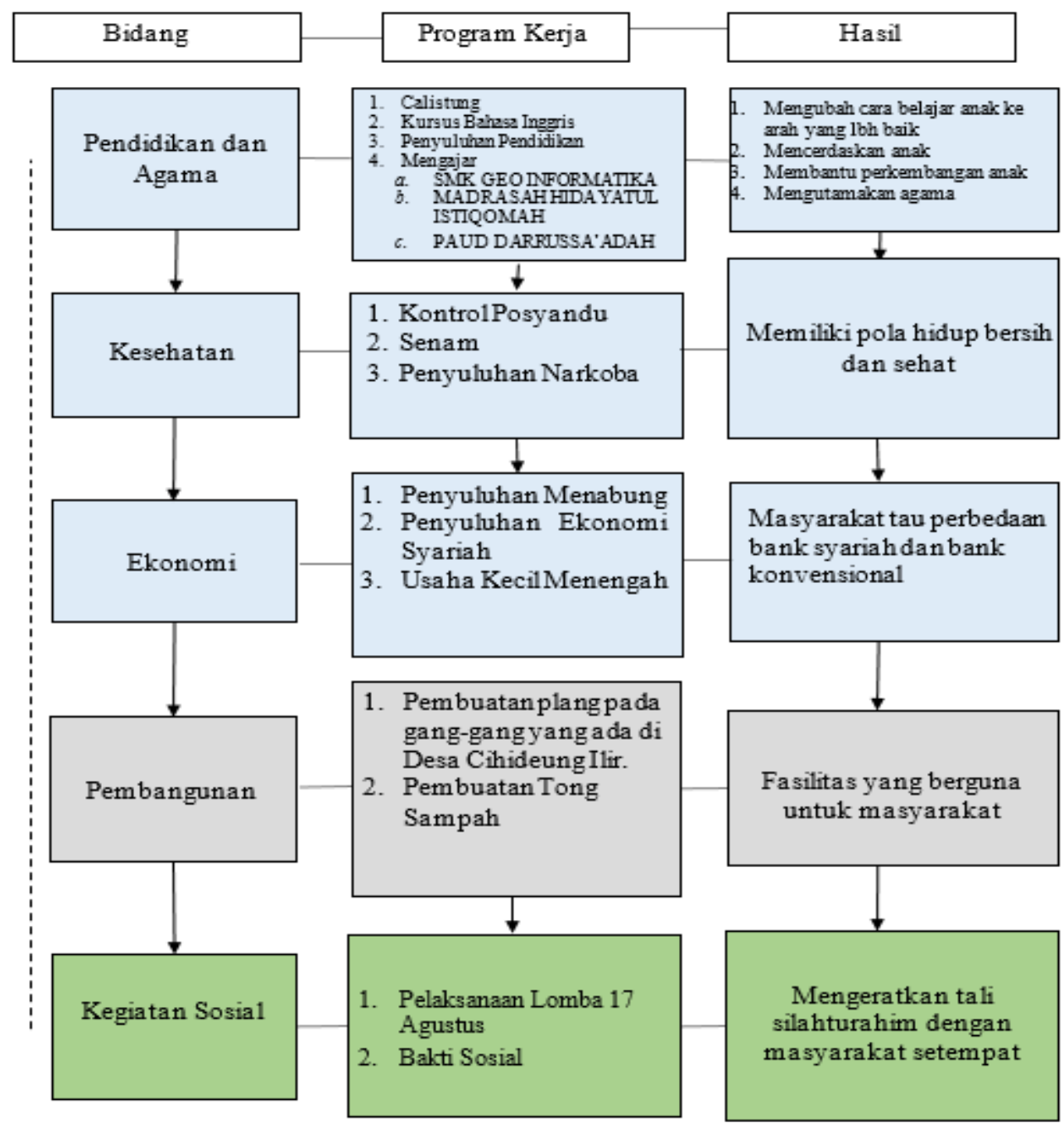

\section{Jadwal Kegiatan}

\begin{tabular}{|c|l|c|c|c|c|}
\hline \multirow{2}{*}{ No } & \multicolumn{1}{|c|}{ Kegiatan } & \multicolumn{4}{|c|}{ Minggu } \\
\cline { 3 - 6 } & & $\mathbf{1}$ & $\mathbf{2}$ & $\mathbf{3}$ & $\mathbf{4}$ \\
\hline 1 & Penyusunan Rencana kegiatan & \multicolumn{4}{|c}{} \\
\hline 2 & Sosialisasi rencana kegiatan & & & \\
\hline 3 & Mengajar PAUD Daarussa'adah & \multicolumn{3}{|c}{} \\
\hline 4 & Mengajar Madrasah Hidayatul Istiqomah & & & \\
\end{tabular}




\begin{tabular}{|c|l|l|l|}
\hline 5 & Mengajar SMK GEO INFORMATIKA & \\
\hline 6 & Pengajian Ibu-ibu & \\
\hline 7 & Calistung & \\
\hline 8 & Kursus Bahasa Inggris & & \\
\hline 9 & Senam & & \\
\hline 10 & Lomba 17-an Desa Cihideung Ilir RT 06 / RW 02 & & \\
\hline 11 & Lomba 17-an PAUD & & \\
\hline 12 & Lomba 17-an SMK GEO INFORMATIKA & & \\
\hline 13 & Kontrol Posyandu & & \\
\hline 14 & Penyuluhan Pendidikan & & \\
\hline 15 & Penyuluhan Penyalahgunaan Narkoba & & \\
\hline 16 & Penyuluhan Pentingnya Menabung & & \\
\hline 17 & Penyuluhan Ekonomi Syariah & & \\
\hline 18 & Pembuatan dan Pemasangan Plang dan Tong & & \\
\hline 19 & sampah & & \\
\hline 20 & Bsaha Kecil Menengah & & \\
\hline
\end{tabular}

\section{Metode Pendekatan}

Program KKN Tematik Terintegrasi Kelompok 17 Desa Cihideung Ilir disusun dalam rangka membantu masyarakat dalam meyelesaikan masalah yang dihadapi dan membawa motivasi dan inovasi terbaru. Dalam hal ini, mengidentifikasi masalah adalah hal yang paling mendasar yang harus dilakukan, sehingga dapat lebih fokus dan terarah dalam melaksanakan program kerja. Adapun program kerja yang disusun melalui beberapa tahap:

\section{a. Tahap Observsi}

Pada tahap pertama ini kami melakukan pendataan di Balai Desa dengan mewawancarai Aparat Desa Cihideung Ilir mengenai kondisi lingkungan, keadaan masyarakat, sarana dan prasarana yang ada, yang meliputi pendidikan, peribadatan, kesehatan, olahraga dan lain-lain. Kemudian kami melakukan silaturahmi kepada ketua RT, ketua RW, tokoh masyarakat, guru, dan tokoh pemuda, untuk melakukan wawancara. Hal ini dimaksudkan untuk mendapatkan gambaran umum dan menggali masalah yang dihadapi oleh masyarakat.

b. Tahap Klasifikasi dan Analisis

Pada tahap ini kami memilih masalahmasalah yang ada menjadi dua kategori, yaitu:, masalah yang sedang, dan masalah yang ringan. Kemudian kami mengalisis dengan kemampuan yang ada mengenai penentuan prioritas masalah yang sekiranya dapat menjadi program kerja kami.

\section{c. Tahap Sosialisasi dan Konfirmasi}

Setelah mengklasifikasi dan mengalisis masalah, kami menyusun program kerja sementara. Setelah itu kami melaporkan kepada pihak desa mengenai program kerja sementara yang sudah tersususun. Sebagai cara dalam mensosialisasikan sekaligus menjaring aspirasi masyarakat di RW 02 / RT 06 terhadap hal-hal apa saja yang mereka butuhkan, kami memilih untuk silahturahmi mengunjungi rumah ketua RW dan RT serta pejabat- pejabat terkait 
setelah melakukan perjanjian masalah waktu sambil membawa dan mempresentasikan program kerja yang telah tersusun.

\section{d. Tahap Penetapan (Fiksasi)}

Setelah menerima masukan dan saran dari berbagai pihak, kami dapat menetapkan mengenai kemungkinan waktu pelaksanaannya. Maka dilakukan pengambilan keputusan secara musyawarah internal kelompok untuk menyusun program kerja secara baku yang menjadi acuan kerja selama Kuliah Kerja Nyata Tematik Terintegrasi di Desa Cihideung Ilir kecamatan Ciampea Kabupaten Bogor.

Program kerja yang telah kami susun tersebut pada kenyataannya tidak hanya bersifat sebagai pemecahan masalah, namun ada juga program kerja yang bersifat partisipatif dan rekreatif.

\section{Partisipasi Masyarakat dalam} Pelaksanaan Program.

Partisipasi masyarakat yang dapat dilakukan dalam kegiatan ini adalah sebagai berikut:

1. Mempersiapkan dan mengerahkan warga Desa Cihideung Ilir RW 02 /
RT 06 untuk mengsukseskan Penyuluhan Penyalahgunaan Narkoba.

2. Menyediakan dengan suka rela Majlis PAUD Daarussa'adah untuk mengsukseskan Penyuluhan Pendidikan, Penyuluhan Ekonomi Syariah, Penyuluhan Pentingnya Menabung.

3. Memberi izin dan mengerahkan anakanak usia dini Desa Cihideung Ilir RW 02 RT 06 untuk mengikuti kegiatan Calistung, Kursus Bahasa Inggris.

4. Memfasilitasi tempat dan peralatan selama pembuatan Plang dikawasan Desa Cihideung Ilir Rw 06 RT 02.

5. Turut membantu dan menyediakan peralatan saat acara 17-an dikawasan Desa Cihideung Ilir Rw 06 RT 02.

6. Meminta izin untuk mengajar selama beberapa minggu di SMK GEO INFORMATIKA, Madrasah Hidayatul Istiqomah, PAUD Darussa'adah.

7. Mempersiapkan dan mengerahkan warga Desa Cihideung Ilir RW 02 / RT 06 untuk mengsukseskan Usaha Kecil Menengah (UKM) 


\section{REALISASI PROGRAM}

Dalam pelaksanaan program dan pembagian tugas program Kuliah Kerja Nyata Tematik Terintegrasi 2018 ini kami melaksanakan beberapa kegiatan dari beberapa bidang sebagai berikut:

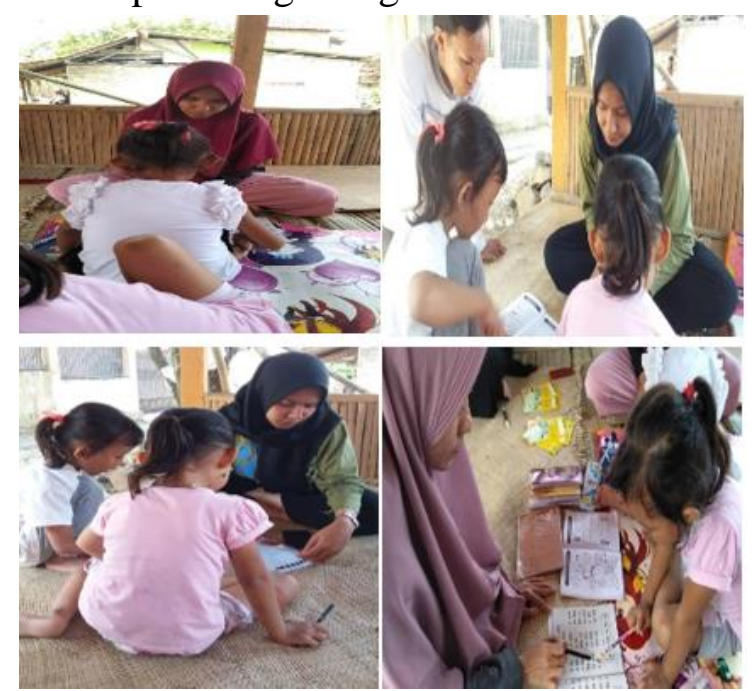

\section{Calistung}
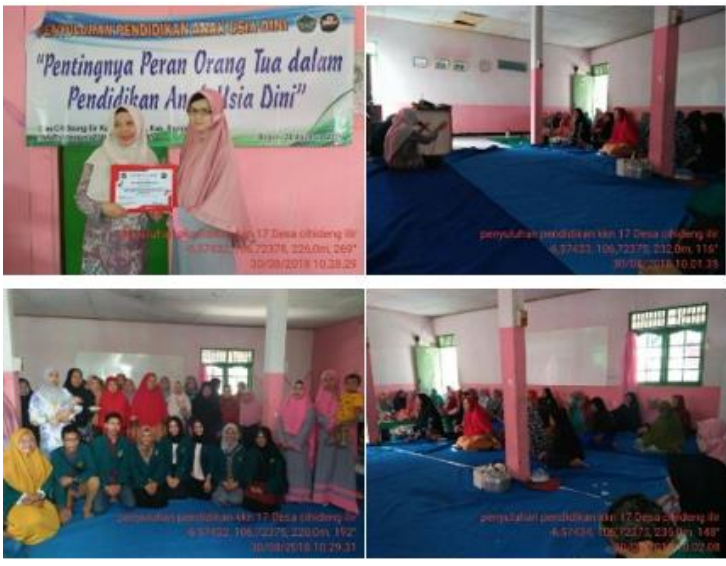

Penyuluhan Pendidikan dan Pengajian IbuIbu
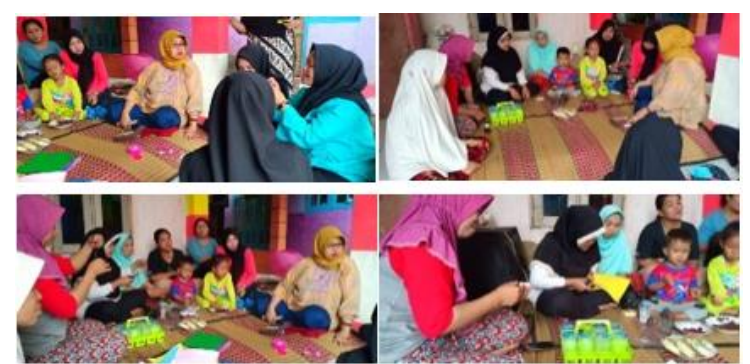

Usaha Kecil Masyarakat
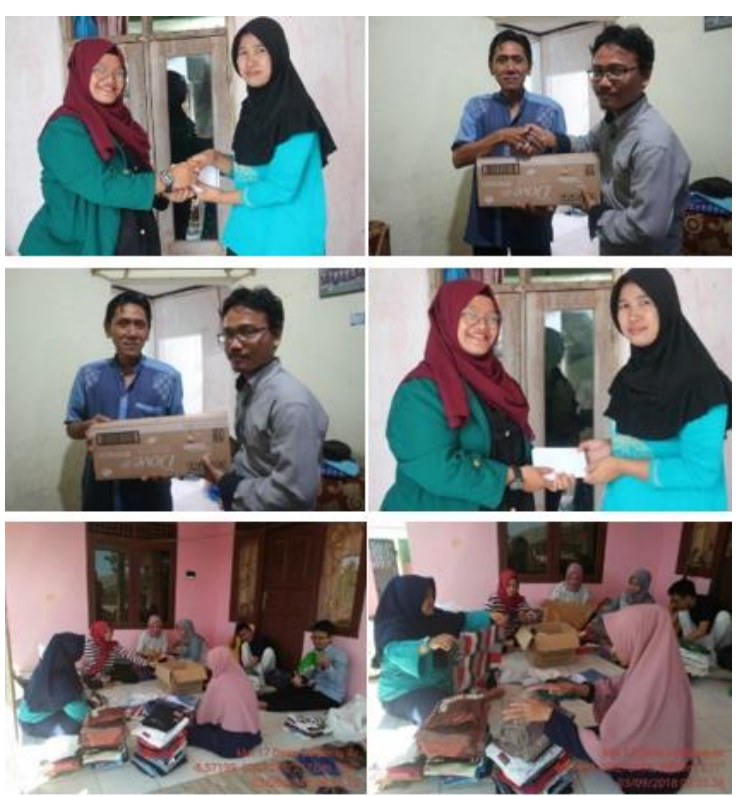

Bakti Sosial dan santunan anak yatim
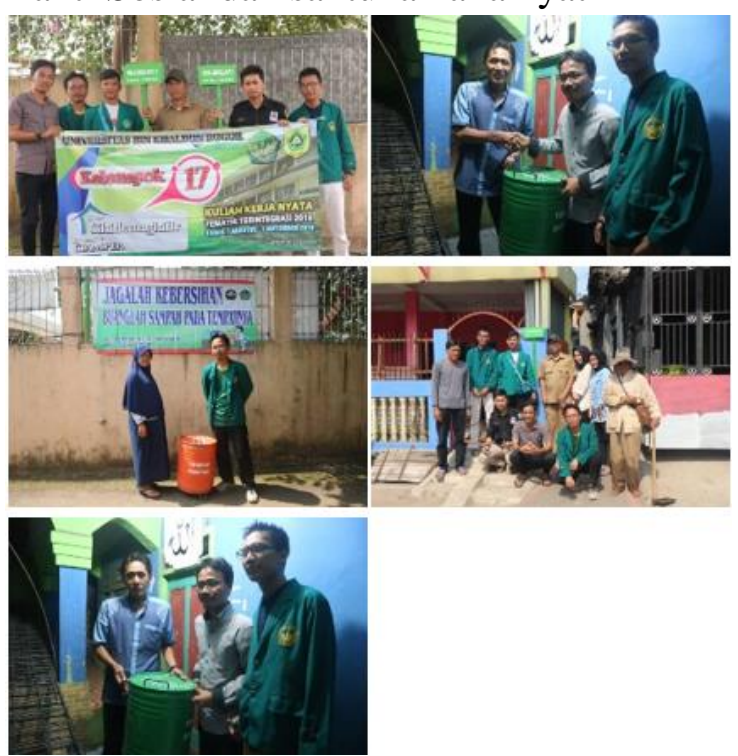

Pembuatan Plang dan tong sampah 


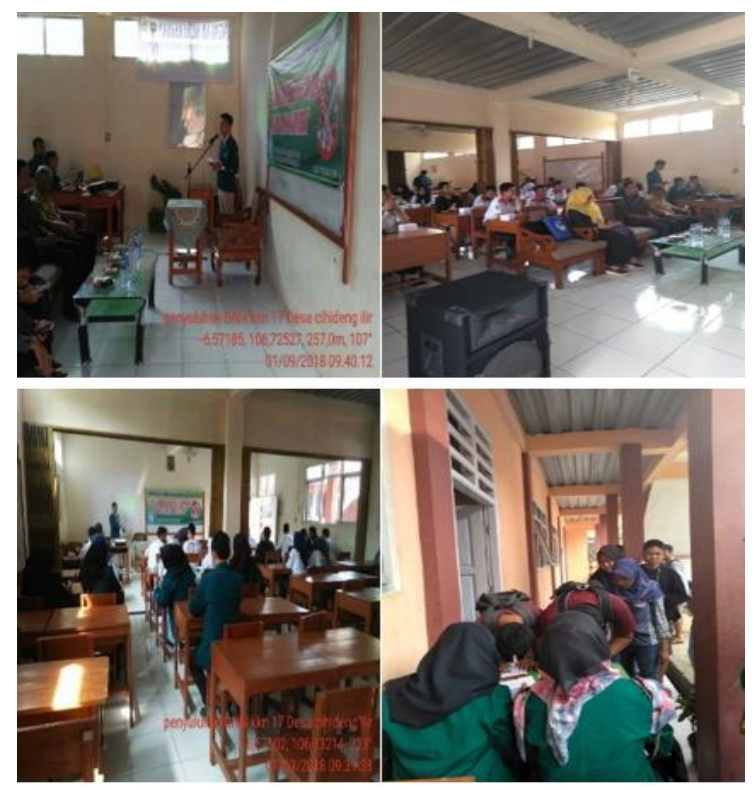

Penyuluhan Penyalahgunaan Narkoba

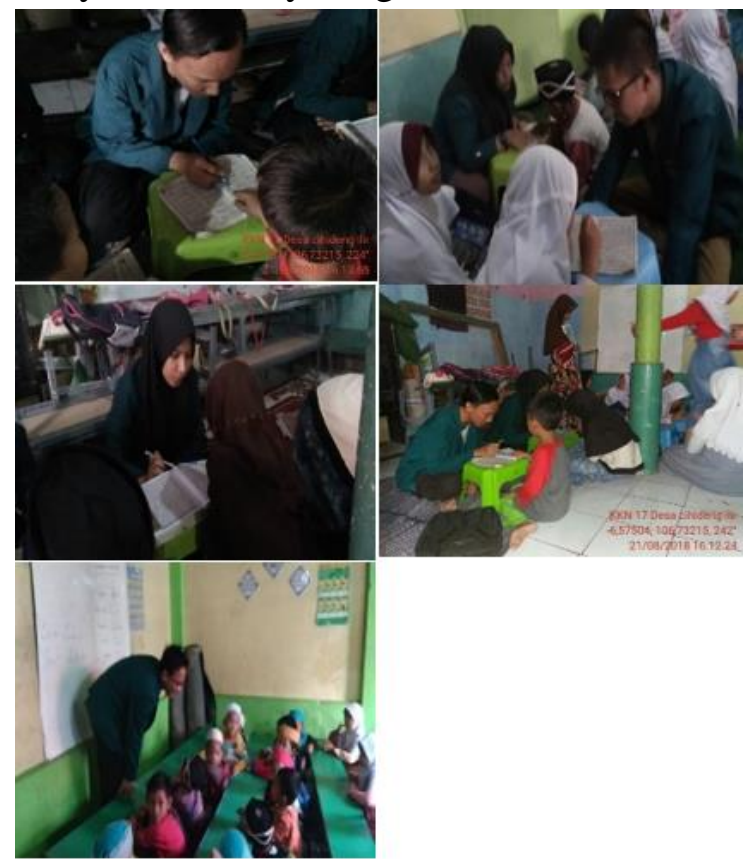

Mengajar Madrasah Hidayatul Istiqomah

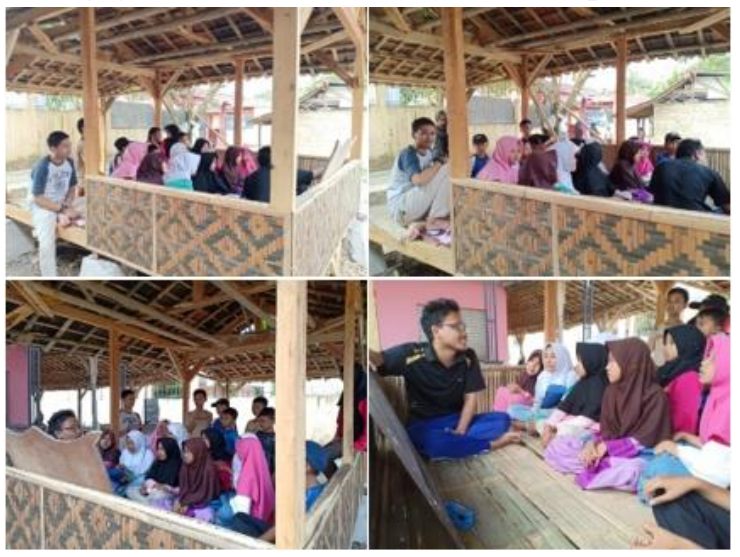

Kursus Bahasa Inggris

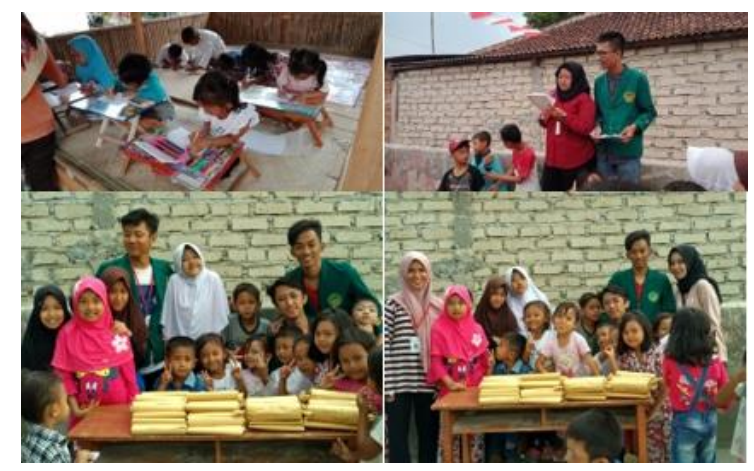

Lomba 17-an Desa Cihideung Ilir

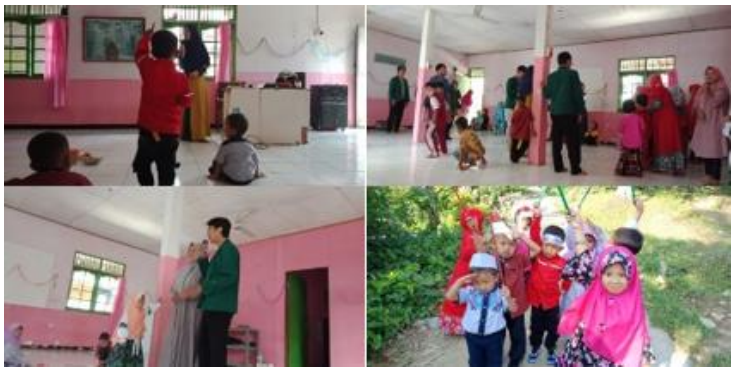

Lomba 17-an PAUD

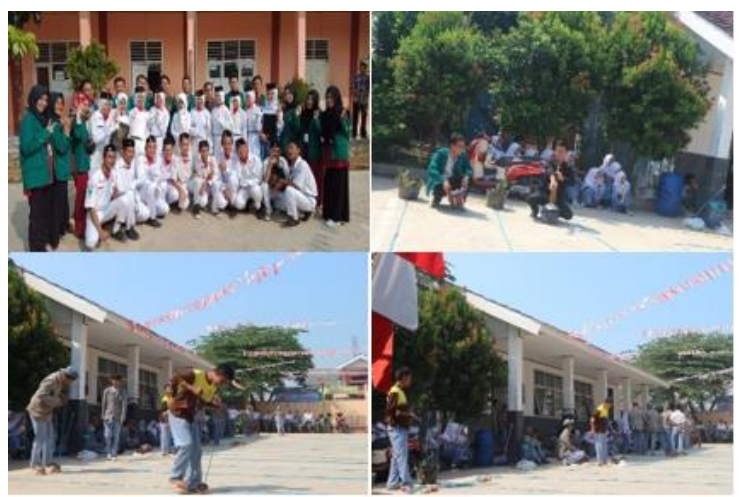

Lomba 17-an SMK GEO INFORMATIKA

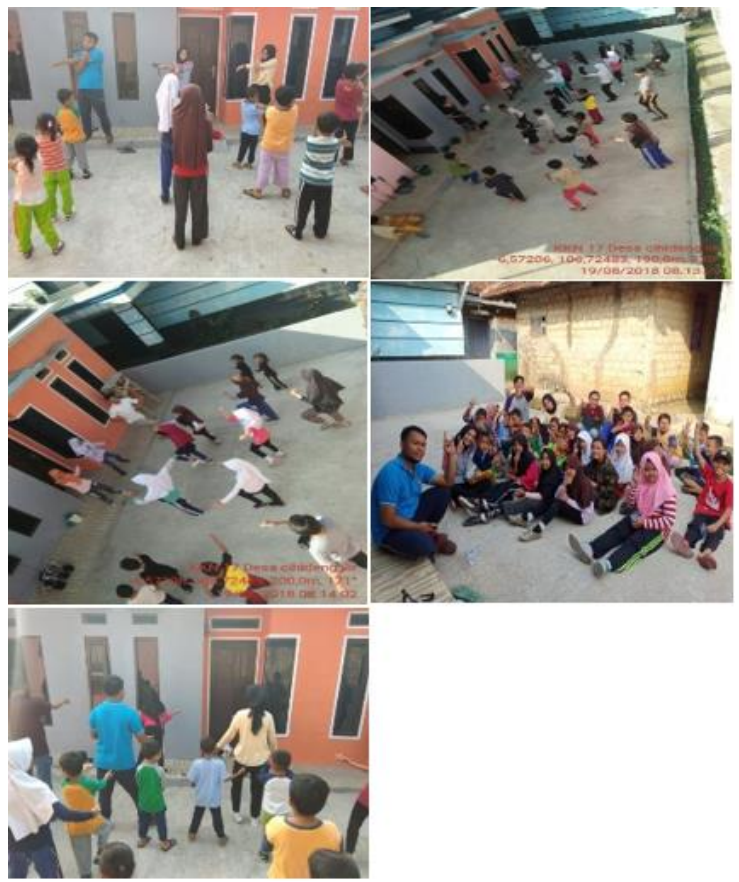

Senam 


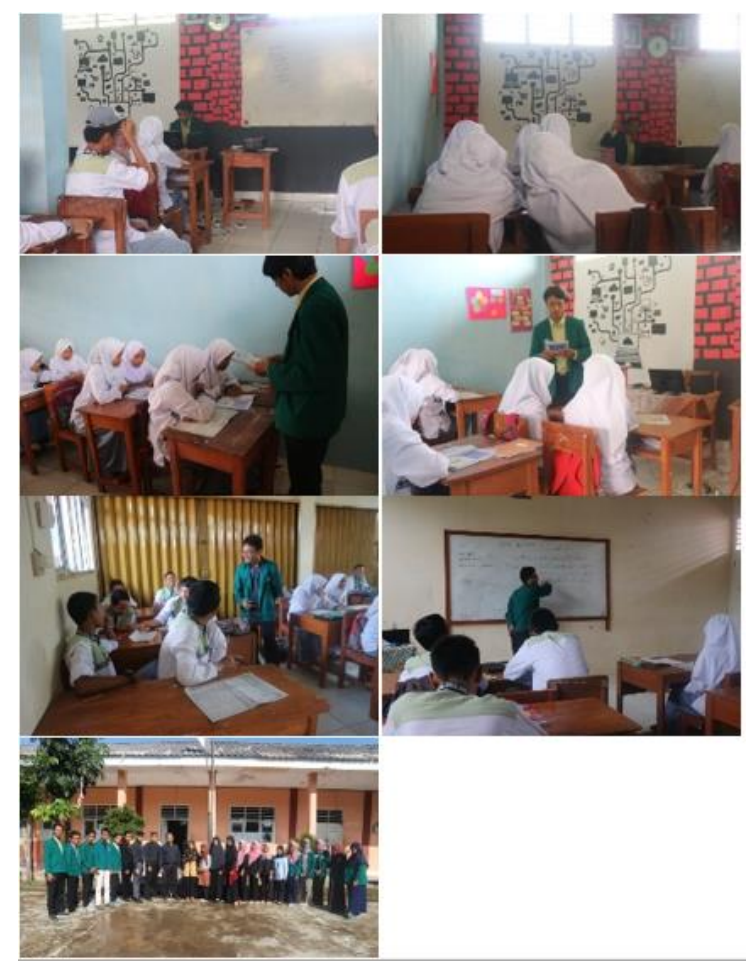

\section{Mengajar SMK GEON INFORMATIKA}

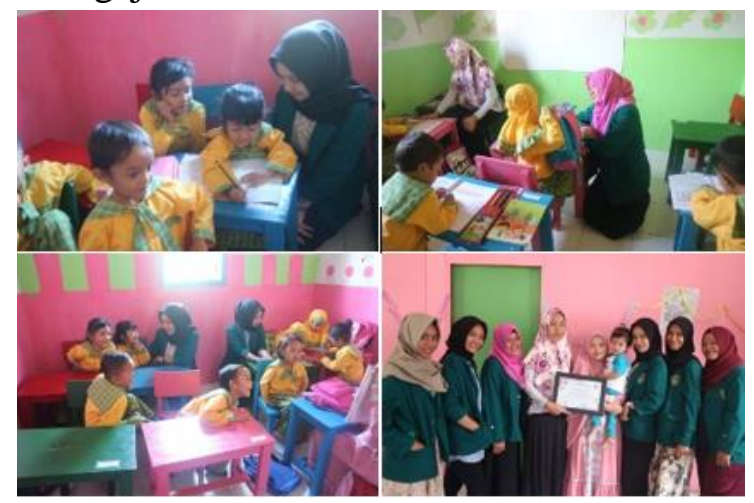

Mengajar PAUD DAARUSSA'ADAH

\section{KESIMPULAN}

Telah terlaksana dan terealisai kegiatan program kami yang berjumlah 18 program kerja dengan lancar, akan tetapi masih jauhnya kami dari kata sempurna karena sempurna hanya milik-Nya yaitu Allah SWT, kami telah mencoba memberikan upaya terbaik kami dan mengambil pelajaran dari msyarakat yang sudah terlebih dahulu merasakan dan mencicipi pahit manisnya kehidupan.

Berikut beberapa kesimpulan yang dapat kami jabarkan selama program KKN yang berlangsung kurang lebih selama 30

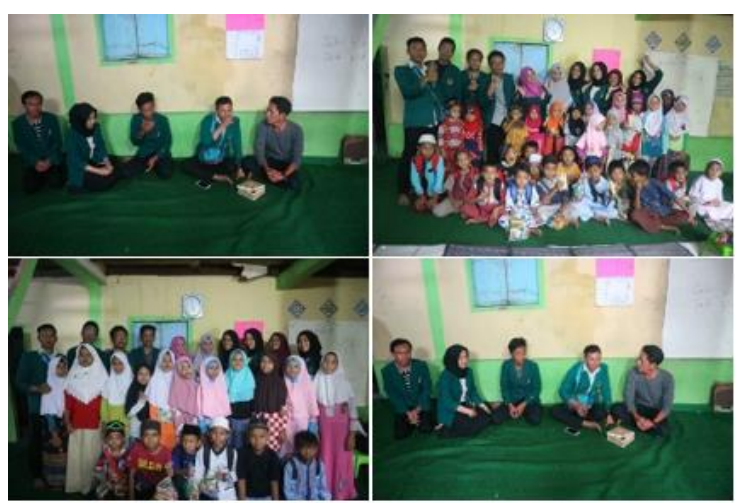

Penyuluhan Ekonomi Syariah dan

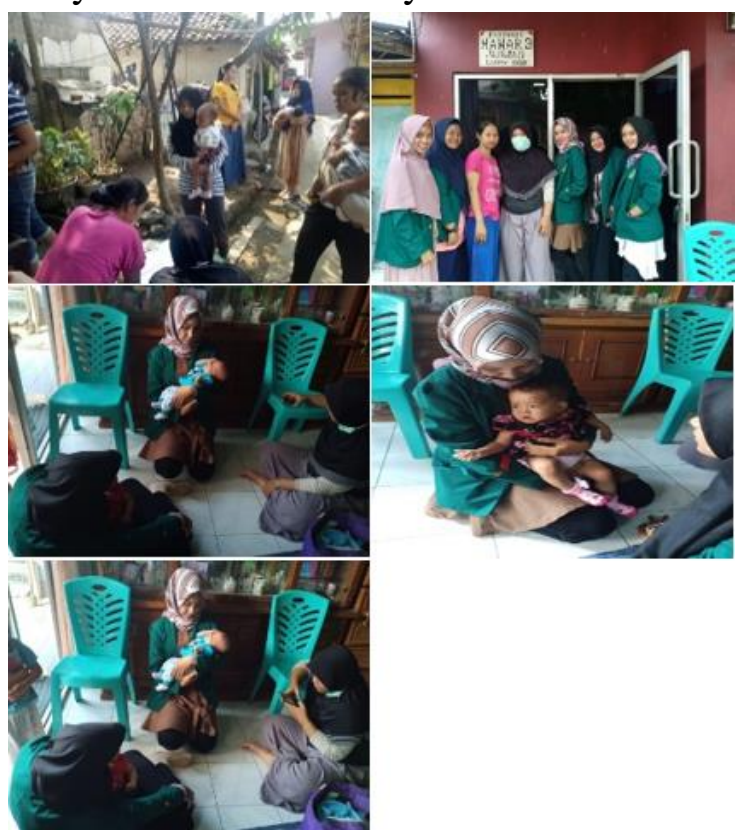

Penyuluhan Pentingnya Menabung

Kontrol Posyandu

hari di Desa Cihideung Ilir Kecamatan Ciampea:

a. Terealisasinya program pengabdian kepada masyarakat yang dilakukan oleh mahasiswa dalam rangka mewujudkan program Universitas Ibn Khaldun Bogor.

b. Terbentuknya Karakter building para Mahasiswa dan Mahasiswi yang mengikuti program KKN ini.

c. Terbentuknya program kerjasama langsung antara Mahasiswa dan 
Masyarakat yang bisa saling bersinergi dan saling menguntungkan.

d. Meningkatkan kepedulian dan rasa empati Mahasiswa kepada permasalahan masyarakat, sehingga terjadinya perubahan perilaku Mahasiswa.

Dampak Bagi Masyarakat

\section{SARAN}

Berikut beberapa saran yang dapat kami jabarkan selama program KKN yang berlangsung kurang lebih selama 30 hari di Desa Cihideung Ilir Kecamatan Ciampea:

a. Sebelum melaksanakan KKN, alangkah baiknya mahasiswa memaksimalkan persiapan diri baik mental, rohani dan jasmani. Agar terhindar dari masalah-masalah terutama kesehatan, dimana selama KKN banyaknya yang jatuh sakit sehingga cukup menghambat jalannya program.

b. Pererat tali silahturahmi dengan warga setempat dan aktifkan kembali para a. memperoleh bantuan pemikiran dan ilmu pengetahuan dalam merencanakan dan melaksanakan pembangunan.

b. Memperoleh cara-cara baru yang di butuhkan untuk merencanakan, merumuskan, dan melaksanakan pembangunan.

pemuda setempat untuk membuat perubahan-perubahan kecil di Desa Cihideung Ilir.

c. Hadirkan tempat yang nyaman dan layak untuk melaksanakan kegiatan posyandu di Desa Cihideung Ilir.

d. Jaga kesehatan dan kebersihan di lingkungan Desa Cihideung Ilir, karena lingkungan yang bersih dan sehat berpengaruh dengan kembang tumbuh anak Desa Cihideung Ilir.

e. Sediakan tempat pembuangan umum agar warga tidak lagi membuang sampah rumah tangga di sungai. 


\section{REFERENSI}

Departemen Pendidikan Nasional Dirjen Dikdasmen Dikmenum, 2002, Pedoman Pengembangan Pendidikan Nasional, Jakarta.

An-Nawawi, Maktabah (Penterjermah). 2018. At-Tibyan Adab Penghafal AlQur'an. Sukoharjo: Penerbit AlQowam.

Kemendikbud. 2014. Pendidikan Agama Islam dan Budi Pekerti Kelas IV. Jakarta: Kemendikbud.

Takdir, Dedy \& AS, H. Muhammad (2015). Kewirausahaan. Penerbit Winajaya Mahadani Karya: Yogyakarta. www.acadeia.edu

"Kewirausahaan". Wikipedia.06 Septeber 2018. 09 Septeber 2018. http://id.wikipedia.org/wiki/Kewirau $\underline{\text { sahaan }}$

Gamming, JK. 2016 .Teknik Pengelasan Yang Baik Dan Benar. (Online) http://www.wirasejati.com/teknik-

pengelasan-yang-baik-dan-

benar.aspx (Diakses 10 September 2018).

Nursamsi, A. (2014). Dalam Skripsi, Manajemen Penghimpunan Dana ZIS Pada Badan Amil Zakat Nasional (BAZNAS) UIN Syarif Hidayatulah.

Anaswir dan Basyirudin Usman. 2002, Media Pembelajaran. Jakarta: Ciputat Press. Warsita, Bambang. 2008, Teknologi Pembelajaran: Landasan dan Aplikasinya, Jakarta: Rineke Cipta

Deni, Arsiandi. 2011 Manfaat Penggunaan Video Sebagai Media Pembelajaran. http://arisandi.com/manfaatpenggunaan-video-sebagai-mediapembelajaran/. Diakses 11 September 2018 09:08pm. 